\title{
Intravascular Metastasis
}

National Cancer Institute

\section{Source}

National Cancer Institute. Intravascular Metastasis. NCI Thesaurus. Code C37192.

Metastasis that involves transfer of malignant cells via the cardiovascular system from one organ or part to another that is not directly connected with it. 